\title{
Fast and simple model for atmospheric radiative transfer
}

\author{
F. C. Seidel ${ }^{1}$, A. A. Kokhanovsky ${ }^{2}$, and M. E. Schaepman ${ }^{1}$ \\ ${ }^{1}$ Remote Sensing Laboratories, University of Zurich, Winterthurerstr. 190, 8057 Zurich, Switzerland \\ ${ }^{2}$ Institute of Environmental Physics, University of Bremen, O. Hahn Allee 1, 28334 Bremen, Germany
}

Received: 2 May 2010 - Published in Atmos. Meas. Tech. Discuss.: 18 May 2010

Revised: 6 August 2010 - Accepted: 16 August 2010 - Published: 25 August 2010

\begin{abstract}
Radiative transfer models (RTMs) are of utmost importance for quantitative remote sensing, especially for compensating atmospheric perturbation. A persistent tradeoff exists between approaches that prefer accuracy at the cost of computational complexity, versus those favouring simplicity at the cost of reduced accuracy. We propose an approach in the latter category, using analytical equations, parameterizations and a correction factor to efficiently estimate the effect of molecular multiple scattering. We discuss the approximations together with an analysis of the resulting performance and accuracy. The proposed Simple Model for Atmospheric Radiative Transfer (SMART) decreases the calculation time by a factor of more than 25 in comparison to the benchmark RTM $6 \mathrm{~S}$ on the same infrastructure. The relative difference between SMART and $6 \mathrm{~S}$ is about $5 \%$ for spaceborne and about $10 \%$ for airborne computations of the atmospheric reflectance function. The combination of a large solar zenith angle (SZA) with high aerosol optical depth (AOD) at low wavelengths lead to relative differences of up to $15 \%$. SMART can be used to simulate the hemispherical conical reflectance factor (HCRF) for spaceborne and airborne sensors, as well as for the retrieval of columnar AOD.
\end{abstract}

\section{Introduction}

The terrestrial atmosphere attenuates the propagation of the solar radiation down to the Earth's surface and back up to a sensor. The scattering and absorption processes involved disturb the retrieval of quantitative information on surface properties. Radiative transfer models (RTMs) and their inversions are commonly used to correct for such effects on the propagation of light. Well-known RTMs are

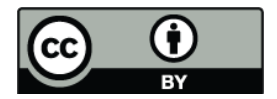

Correspondence to: F. C. Seidel (felix.seidel@geo.uzh.ch)
6S (Second Simulation of a Satellite Signal in the Solar Spectrum) (Vermote et al., 1997), SCIATRAN (Rozanov et al., 2005), SHARM (Muldashev et al., 1999; Lyapustin, 2005), RT3 (Evans and Stephens, 1991), RTMOM (Govaerts, 2006), RAY (Zege and Chaikovskaya, 1996), STAR (Ruggaber et al., 1994) and Pstar2 (Nakajima and Tanaka, 1986; Ota et al., 2010), as well as DISORT (Stamnes et al., 1988), which is used in MODTRAN (Berk et al., 1989), STREAMER (Key and Schweiger, 1998) and SBDART (Ricchiazzi et al., 1998). These accurate but complex RTMs are frequently run in a forward mode, generating look-up tables (LUTs), which are later used during the inversion process for atmospheric compensation (Gao et al., 2009) or aerosol retrieval (Kokhanovsky, 2008; Kokhanovsky and Leeuw, 2009; Kokhanovsky et al., 2010), for instance. There are also a series of highly accurate, but computationally intensive Monte Carlo photon transport codes available. However, the best accuracy may not be always desirable for a RTM. Approximative equations have been developed before computers were widely available (Hammad and Chapman, 1939; Sobolev, 1972). With regard to the growing size and frequency of remote sensing datasets, approximative and computationally fast RTMs are becoming relevant again (Kokhanovsky, 2006; Katsev et al., 2010; Carrer et al., 2010). In particular, RTMs of the vegetation canopy and further algorithms that exploit data from imaging spectroscopy instruments (Itten et al., 2008) often rely on fast atmospheric RTM calculations.

In this context, we propose the fast Simple Model for Atmospheric Radiative Transfer (SMART). It is based on approximative analytical equations and parameterizations, which represent an favourable balance between speed and accuracy. We consider minimised complexity and computational speed as important assets for downstream applications and define an acceptable uncertainty range of up to $5-10 \%$ for the modelled reflectance factor at the sensor level, under typical mid-latitude remote sensing conditions. SMART can

Published by Copernicus Publications on behalf of the European Geosciences Union. 
therefore be used as a physical model, maintaining a causeand-effect relationship in atmospheric radiative transfer. Instead of depending on the classic LUT approach, it permits parameter retrieval in near-real-time. This enables the rapid assessment of regional data requiring exhaustive correction, such as imaging spectrometer data. Furthermore, it supports the straightforward inversion of aerosol optical depth (AOD; $\tau_{\lambda}^{\text {aer }}$ ) by implementing radiative transfer equations as a function of $\tau_{\lambda}^{\text {aer }}$. The theoretical feasibility for the retrieval of aerosols in terms of the sensor performance was shown in Seidel et al. (2008) for the APEX instrument (Itten et al., 2008).

In this paper, we describe the two-layer atmospheric model with the implementation of approximative radiative transfer equations in both layers and at the Earth's surface. We then assess the accuracy and performance of SMART in comparison with $6 \mathrm{~S}$.

\section{SMART - a simple model for atmospheric radiative transfer}

A remote sensing instrument measures the spectral radiance as a function of the spectral atmospheric properties and the illumination/observation geometry $L_{\lambda}\left(\tau_{\lambda}, P_{\lambda}(\Theta), \omega_{\lambda} ; \mu_{0}, \mu, \phi-\phi_{0}\right)$, where $\tau_{\lambda}$ is the optical depth, $P_{\lambda}(\Theta)$ is the phase function at the scattering angle $\Theta$, $\omega_{\lambda}$ is the single scattering albedo, $\mu_{0}=\cos \theta_{0}, \mu=\cos \theta, \theta_{0}$ and $\theta$ represent the solar and viewing zenith angles (SZA, VZA), $\phi-\phi_{0}$ is the relative azimuth between viewing $\phi$ and solar direction $\phi_{0}$. However, from a modelling perspective, it is more convenient to use a dimensionless reflectance function. The relationship between radiance and reflectance is given by:

$R_{\lambda}=\frac{\pi L_{\lambda}}{\mu_{0} F_{0, \lambda}}$,

where $F_{0, \lambda}$ is the spectral solar flux or irradiance on a unit area perpendicular to the beam. For readability, we omit the arguments. The subscripted wavelength denotes spectral dependence.

SMART assumes a plane-parallel, two-layer atmosphere. We will use the superscript I to denote the upper layer, superscript II for the lower layer. While the lower layer contains aerosol particles and molecules, the upper layer contains only molecules. The surface elevation, the transition altitude of the two layers, as well as the top-of-atmosphere (TOA) altitude can be chosen freely. The planetary boundary layer (PBL) height is a good estimate for the vertical extent of the lower layer. The sensor altitude can be set to any altitude within the atmosphere or to the TOA. Altitudes are related to air pressure $p$ according to the hydrostatic equation. This 1-D coordinate system is used in Eqs. (3) and (25) to determine $\tau_{\lambda}$ and to scale the atmospheric reflectance and transmittance function corresponding to a specific altitude within atmosphere.
SMART accepts any combination of $\tau_{\lambda}, \theta_{0}, \theta$ and $\lambda$. The current implementation executes on the 2-D array $\left[\lambda, \tau_{550 \mathrm{~nm}}^{\mathrm{aer}}\right]$, where $\lambda \in[400 \mathrm{~nm}, 800 \mathrm{~nm}]$ and $\tau_{550 \mathrm{~nm}}^{\mathrm{aer}} \in$ $[0.0,0.5]$. The spectral dependence of the AOD is approximated by:

$\tau_{\lambda}^{\mathrm{aer}}=\tau_{550 \mathrm{~nm}}^{\mathrm{aer}}\left(\frac{\lambda}{550 \mathrm{~nm}}\right)^{-\alpha}$,

according to Ångström's law (Ångström, 1929). Aerosol optical properties, such as the asymmetry factor $g_{\lambda}^{\text {aer }}, \omega_{\lambda}^{\text {aer }}$ and the Ångström parameter $\alpha$ are taken from d'Almeida et al. (1991) for the following aerosol models: cleancontinental, average-continental, urban, clean-maritime, maritime-polluted and maritime-mineral.

\subsection{Radiative transfer in layer I}

By definition, the layer I contains no aerosols and the total optical depth is therefore given by the molecular optical depth $\tau_{\lambda}^{\mathrm{I}}=\tau_{\lambda}^{\mathrm{mlc}}\left(1-h^{\mathrm{PBL}}\right)$, where

$h^{\mathrm{PBL}}=\frac{p^{\mathrm{SFC}}-p^{\mathrm{PBL}}}{p^{\mathrm{SFC}}-p^{\mathrm{TOA}}}$

is the relative height of the PBL within the atmosphere. It ranges from 0 at the surface (SFC) to 1 at TOA. Values for $\tau_{\lambda}^{\mathrm{mlc}}$ are computed using semi-empirical equations from Bodhaine et al. (1999).

The downward total transmittance $T_{\lambda}^{\mathrm{I} \downarrow}$ is the sum of the downward direct transmittance $T_{\lambda}^{\mathrm{I} \downarrow \text { dir }}$ and the downward diffuse transmittance $T_{\lambda}^{\mathrm{I} \downarrow \mathrm{dfs}}$ :

$T_{\lambda}^{\mathrm{I} \downarrow}=T_{\lambda}^{\mathrm{I} \downarrow \text { dir }}+T_{\lambda}^{\mathrm{I} \downarrow \mathrm{dfs}}=e^{-\frac{\tau_{\lambda}^{\mathrm{I}}}{\mu_{0}}}+\tau_{\lambda}^{\mathrm{I}} e^{\left(-u_{0}-v_{0} \tau_{\lambda}^{\mathrm{I}}-w_{0}\left(\tau_{\lambda}^{\mathrm{I}}\right)^{2}\right)}$.

$T_{\lambda}^{\mathrm{I} \downarrow \mathrm{dfs}}$ is approximated by using a fast and accurate parameterization suggested by Kokhanovsky et al. (2005) for $\omega_{\lambda}=1$, where

$u_{0}=\sum_{m=0}^{3} h_{m} \mu_{0}^{m}$,

$v_{0}=p_{0}+p_{1} e^{-p_{2} \mu_{0}}$,

$w_{0}=q_{0}+q_{1} e^{-q_{2} \mu_{0}}$.

The constants $p_{0}, q_{0}, p_{1}, q_{1}, p_{2}, q_{2}$ and $h_{m}$ are parameterized using polynomial expansions with respect to $g_{\lambda}$, e.g.

$p_{0}=\sum_{s=0}^{3} p_{0, s} g_{\lambda}$.

$p_{0, s}$ and all other expansion coefficients are given in Kokhanovsky et al. (2005). The upward transmittance $T_{\lambda}^{\mathrm{I} \uparrow}$ is defined according to Eqs. (4) to (8) by substituting $\mu_{0}, u_{0}$, $v_{0}, w_{0}$ for $\mu, u, v, w$, respectively. 


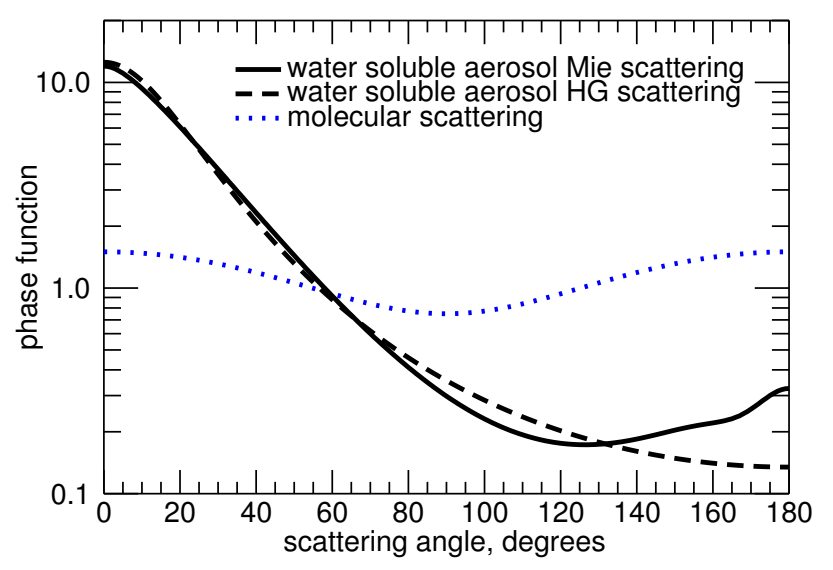

Fig. 1. Phase functions at $550 \mathrm{~nm}$ for molecules and dry water soluble aerosols derived from the Henyey-Greenstein (HG) approximation with $g_{550 \mathrm{~nm}}^{\mathrm{aer}}=0.63$ and the exact Lorenz-Mie theory.

The transmitted light is scattered in all directions. The ratio of scattering to total light extinction $\omega_{\lambda}$ and the angular distribution of the scattered light $P_{\lambda}(\Theta)$ are used to describe the scattering process. To simplify the approach, the total intrinsic atmospheric scattering function can be decomposed into the single scattering approximation (SSA) and multiple scattering (MS). The first order atmospheric reflectance function $R_{\lambda}^{\mathrm{I}, \mathrm{SSA}}$ can be expressed using the analytical equation as given in van de Hulst (1948); Sobolev (1972); Hansen and Travis (1974); Kokhanovsky (2006):

$R_{\lambda}^{\mathrm{I}, \mathrm{SSA}}=\frac{\omega_{\lambda}^{\mathrm{mlc}} P_{\lambda}^{\mathrm{mlc}}(\Theta)}{4\left(\mu_{0}+\mu\right)}\left(1-e^{-m \tau_{\lambda}^{\mathrm{I}}}\right)$,

where the molecular single scattering albedo $\omega_{\lambda}^{\mathrm{mlc}}:=1$ and the molecular (Rayleigh) scattering phase function for reflected, unpolarised solar radiation is given by:

$P_{\lambda}^{\mathrm{mlc}}(\Theta)=\frac{3}{4}\left(1+\cos ^{2} \Theta\right)$

with the scattering angle

$\Theta=\arccos \left[-\mu_{0} \mu+\cos \left(\phi-\phi_{0}\right) \sqrt{\left(1-\mu_{0}\right)(1-\mu)}\right]$

and the geometrical air mass factor $m=\left(\mu_{0}^{-1}+\mu^{-1}\right)$. $P_{\lambda}^{\mathrm{mlc}}(\Theta)$ is plotted in Fig. 1.

Standard RTMs spend most of their computational time calculating multiple scattering with iterative integration procedures. In the case of layer I, we therefore suggest a generic correction factor $f^{\text {corr }}$ to approximate Rayleigh multiple scattering. We derive one $f^{\text {corr }}$ per SZA as a function of $\lambda$ and $\tau$ from accurate MODTRAN/DISORT calculations, however without polarisation. The correction factor is de- fined as the ratio between the total reflectance and the SSA at sensor level:

$f_{\mu_{0}}^{\text {corr }}(\lambda, \tau)=\frac{R_{\lambda}^{\text {sensor,MODTRAN }}}{R_{\lambda}^{\text {sensor,SSA,MODTRAN }}}$

The total reflectance function of layer $\mathrm{I}$ is then given by Eqs. (9) and (12):

$$
R_{\lambda}^{\mathrm{I}}=R_{\lambda}^{\mathrm{I}, \mathrm{mlc}}=\frac{\omega_{\lambda}^{\mathrm{mlc}} P_{\lambda}^{\mathrm{mlc}}(\Theta)}{4\left(\mu_{0}+\mu\right)}\left(1-e^{-m \tau_{\lambda}^{\mathrm{I}}}\right) f_{\mu_{0}}^{\mathrm{corr}}
$$

\subsection{Radiative transfer in layer II}

The down- and upward total transmittances $T_{\lambda}^{\mathrm{II} \downarrow}, T_{\lambda}^{\mathrm{II} \uparrow}$ in layer II are calculated according to Eq. (4) by using $g_{\lambda}^{\text {aer }}$ and substituting $\tau_{\lambda}^{\mathrm{I}}$ to the total spectral optical depth of layer II $\tau_{\lambda}^{\mathrm{II}}=\tau_{\lambda}^{\mathrm{aer}}+\tau_{\lambda}^{\mathrm{mlc}} h^{\mathrm{PBL}}$.

The atmospheric reflectance function of layer II is simplified by the decomposition into molecular and aerosol parts. As a consequence, the aerosol-molecule scattering interactions are neglected. The related error is examined in Sect. 3.3. The molecular reflectance function $R_{\lambda}^{\mathrm{II}, \mathrm{mlc}}$ is derived directly from Eq. (13), where $\tau_{\lambda}^{\mathrm{I}}$ is changed to $\tau_{\lambda}^{\mathrm{mlc}} h^{\mathrm{PBL}}$. Thus, the total reflectance function of layer II is given by:

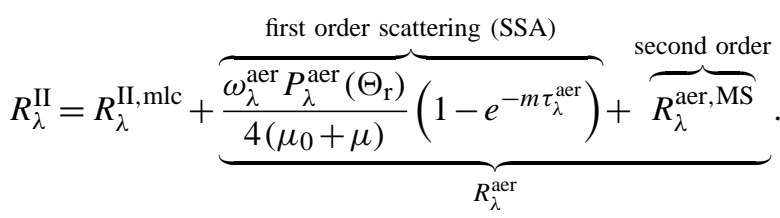

The aerosol scattering phase function $P_{\lambda}^{\text {aer }}(\Theta)$ is defined by the approximate Henyey-Greenstein (HG) phase function (Henyey and Greenstein, 1941), which depends on the aerosol asymmetry factor $g_{\lambda}^{\text {aer }}$ and the scattering angle $\Theta$ :

$P_{\lambda}^{\mathrm{aer}}(\Theta)=\frac{1-\left(g_{\lambda}^{\mathrm{aer}}\right)^{2}}{\left[1+\left(g_{\lambda}^{\mathrm{aer}}\right)^{2}-2 g_{\lambda}^{\mathrm{aer}} \cos \Theta\right]^{2 / 3}}$

This HG phase function is plotted in Fig. 1 with $g_{550 \mathrm{~nm}}^{\text {aer }}=$ 0.63 for a dry water soluble aerosol according to d'Almeida et al. (1991). The exact phase function derived from the Lorenz-Mie theory is superimposed to illustrate the imperfection of the $\mathrm{HG}$ approximation in the forward scattering domain for $\Theta>150^{\circ}$. This influence on the accuracy of SMART is discussed in the second half of Sect. 3.2.

The second order (or secondary) scattering is calculated according to the Successive Orders of Scattering (SOS) 
method described by Hansen and Travis (1974):

$$
\begin{aligned}
& R^{\mathrm{aer}, \mathrm{MS}}\left(\mu, \mu_{0}, \phi-\phi_{0}\right)=\frac{\tau^{\mathrm{aer}} \omega^{\text {aer }}}{4 \pi} \\
& \int_{0}^{2 \pi} \int_{0}^{1}\left[\frac{1}{\mu} P_{\mathrm{t}}^{\mathrm{aer}}\left(\mu, \mu^{\prime}, \phi-\phi^{\prime}\right) R^{\mathrm{SSA}}\left(\mu^{\prime}, \mu_{0}, \phi^{\prime}-\phi_{0}\right)\right. \\
& +\frac{1}{\mu_{0}} R^{\mathrm{SSA}}\left(\mu, \mu^{\prime}, \phi-\phi^{\prime}\right) P_{\mathrm{t}}^{\mathrm{aer}}\left(\mu^{\prime}, \mu_{0}, \phi^{\prime}-\phi_{0}\right) \\
& -\frac{e^{-\frac{\tau^{\mathrm{aer}}}{\mu_{0}}}}{\mu_{0}} T^{\mathrm{SSA}}\left(\mu, \mu^{\prime}, \phi-\phi^{\prime}\right) P_{\mathrm{r}}^{\mathrm{aer}}\left(\mu^{\prime}, \mu_{0}, \phi^{\prime}-\phi_{0}\right) \\
& \left.-\frac{e^{-\frac{\tau^{\mathrm{aer}}}{\mu}}}{\mu} P_{\mathrm{r}}^{\mathrm{aer}}\left(\mu, \mu^{\prime}, \phi-\phi^{\prime}\right) T^{\mathrm{SSA}}\left(\mu^{\prime}, \mu_{0}, \phi^{\prime}-\phi_{0}\right)\right] d \mu^{\prime} d \phi^{\prime} .
\end{aligned}
$$

$\lambda$ and other non-angular arguments are omitted for the sake of readability. $P_{\mathrm{r}}^{\text {aer }}$ and $P_{\mathrm{t}}^{\text {aer }}$ denote the aerosol HG phase function (Eq. 15) using the scattering angle $\Theta_{\mathrm{r}}$ in case of reflectance (Eq. 11) and the scattering angle

$$
\Theta_{\mathrm{t}}=\arccos \left[\mu_{0} \mu+\cos \left(\phi-\phi_{0}\right) \sqrt{\left(1-\mu_{0}\right)(1-\mu)}\right]
$$

in case of transmittance. The single scattering transmittance $T^{\text {SSA }}$ is given in van de Hulst (1948); Sobolev (1972); Hansen and Travis (1974); Kokhanovsky (2006):

$T_{\lambda}^{\mathrm{SSA}}=\frac{\omega_{\lambda}^{\mathrm{aer}} P_{\lambda}^{\mathrm{aer}}\left(\Theta_{\mathrm{t}}\right)}{4\left(\mu_{0}-\mu\right)}\left(e^{-\frac{\tau_{\lambda}^{\mathrm{aer}}}{\mu_{0}}}-e^{-\frac{\tau_{\lambda}^{\mathrm{aer}}}{\mu}}\right)$.

In case of $\mu_{0}=\mu$, we modify Eq. (18) to avoid indeterminacy with l'Hôpital's (Bernoulli's) rule:

$T_{\lambda}^{\mathrm{SSA}}=\frac{\omega_{\lambda}^{\mathrm{aer}} P_{\lambda}^{\mathrm{aer}}\left(\Theta_{\mathrm{t}}\right)}{4 \mu^{2}} \tau_{\lambda}^{\mathrm{aer}} e^{\left(-\frac{\tau_{\lambda}^{\mathrm{aer}}}{\mu}\right)}$.

We use a numerical approximation to calculate the integrals of Eq. (16). This is by far the most computationally intensive step in SMART. Therefore, we currently neglect scattering orders higher than two. A third order term could be added to Eq. (16) as given by Hansen and Travis (1974). However, for our accuracy requirements and under favourable remote sensing conditions, second order scattering is sufficient. More details are given in the first half of Sect. 3.2.

If fast computation is more important than accuracy, $R_{\lambda}^{\text {aer,MS }}$ can be substituted by $\cdot f_{\mu_{0}}^{\text {corr }}\left(\lambda, \tau_{550 \mathrm{~nm}}^{\text {aer }}\right)$ in analogy to Eq. (12). The expense is roughly $20 \%$ in decreased accuracy.

\subsection{Radiative transfer at the surface}

The modelling of optical processes at the surface can be elaborate due to adjacency and directional effects. Here we assume the simple case with isotropically reflected light on a homogeneous surface according to Lambert's law (Ångström, 1925; Chandrasekhar, 1960; Sobolev, 1972):

$R_{\lambda}^{\mathrm{SFC}}=\frac{a_{\lambda}}{1-s_{\lambda} a_{\lambda}}$, where $a_{\lambda}$ is the surface albedo and $s_{\lambda}$ is the spherical albedo to account for multiple interaction between surface and atmosphere. We use the parameterization suggested by Kokhanovsky et al. (2005) for $s_{\lambda}$, where:

$s_{\lambda}=\tau_{\lambda}^{\mathrm{II}}\left(a e^{-\frac{\tau_{\lambda}^{\mathrm{II}}}{\alpha}}+b e^{-\frac{\tau_{\lambda}^{\mathrm{II}}}{\beta}}+c\right)$.

The constants $a, \alpha, b, \beta$ and $c$ are parameterized according to Eq. (8). The corresponding expansion coefficients are given in Kokhanovsky et al. (2005). The resulting $R_{\lambda}^{\mathrm{SFC}}$ is also known as the hemispherical conical reflectance factor (HCRF) according to Schaepman-Strub et al. (2006).

\subsection{At-sensor reflectance function}

Finally, we put the above equations together along the optical path to resolve the reflectance function $R_{\lambda}^{\mathrm{S}}$. Multiple retroreflections between layers I and II are neglected. A sensor at TOA or within levels I or II is simulated as follows:

$R_{\lambda}^{\mathrm{S}, \mathrm{TOA}}=R_{\lambda}^{\mathrm{I}}+T_{\lambda}^{\mathrm{I} \downarrow}\left[R_{\lambda}^{\mathrm{II}}+R_{\lambda}^{\mathrm{SFC}} T_{\lambda}^{\mathrm{II} \uparrow}\right] T_{\lambda}^{\mathrm{I} \uparrow}$,

$R_{\lambda}^{\mathrm{S}, \mathrm{I}}=R_{\lambda}^{\mathrm{I}} s h^{\mathrm{I}}+T_{\lambda}^{\mathrm{I} \downarrow}\left[R_{\lambda}^{\mathrm{II}}+R_{\lambda}^{\mathrm{SFC}} T_{\lambda}^{\mathrm{II} \uparrow}\right]\left(1-s h^{\mathrm{I}}+s h^{\mathrm{I}} T_{\lambda}^{\mathrm{I} \uparrow}\right)$,

$R_{\lambda}^{\mathrm{S}, \mathrm{II}}=T_{\lambda}^{\mathrm{I} \downarrow}\left[R_{\lambda}^{\mathrm{II}} s h^{\mathrm{II}}+T_{\lambda}^{\mathrm{II} \downarrow} R_{\lambda}^{\mathrm{SFC}}\left(1-s h^{\mathrm{II}}+s h^{\mathrm{II}} T_{\lambda}^{\mathrm{II} \uparrow}\right)\right]$

where $T_{\lambda}^{\mathrm{II} \uparrow}:=T_{\lambda}^{\mathrm{II} \downarrow} T_{\lambda}^{\mathrm{II} \uparrow}$,

$s h^{\mathrm{I}}=\frac{p^{\mathrm{PBL}}-p^{\text {Sensor }}}{p^{\mathrm{PBL}}-p^{\mathrm{TOA}}}$ and $s h^{\mathrm{II}}=\frac{p^{\mathrm{SFC}}-p^{\text {Sensor }}}{p^{\mathrm{SFC}}-p^{\mathrm{PBL}}}$.

These scaling factors are used to account for the relative height of the sensor within the corresponding layer. $s h^{\mathrm{I}}$ ranges from 1 at TOA to 0 at the PBL, while $s h^{\mathrm{II}}$ varies from 1 at the PBL to 0 at the Earth's surface (SFC).

\section{Accuracy assessment}

For typical airborne remote sensing conditions in the midlatitudes we choose the representative uncertainty of imaging spectroscopy data of approximately 5\% (Itten et al., 2008) as the accuracy requirement for SMART. Less typical conditions are analysed as well; in these cases we will accept larger errors. The definition of the conditions is given in Table 1. The AOD range was chosen according to the findings of Ruckstuhl et al. (2008), the wavelength range selected with regard to the optimal sensor performance (Seidel et al., 2008), while also avoiding strong water vapour absorption. We assume a black surface at the sea level $\left(a_{\lambda}=0\right)$ to focus on the atmospheric part of SMART. Furthermore, we solely use the nadir viewing direction $(\mu=1)$, which is approximated by small field-of-view sensors $\left(\mathrm{FOV}<30^{\circ}\right)$.

This section evaluates if the prior accuracy requirements can be met by SMART. We compare SMART with 
Table 1. Definition of the conditions and the related accuracy requirements for SMART. The limited conditions refer to typical airborne remote sensing needs in the mid-latitudes, which SMART was developed for. The analysed conditions refer to the accuracy assessment.

\begin{tabular}{lcc}
\hline remote sensing conditions & limited & analysed \\
\hline$\tau_{550 \mathrm{~nm}}^{\text {aer }}$ & $0-0.5$ & $0-0.5$ \\
solar zenith angle, degrees & $20-60$ & nadir-70 \\
viewing zenith angle & nadir & nadir \\
wavelength, nm & $500-700$ & $400-800$ \\
surface albedo & 0 & 0 \\
accuracy requirement, $\%$ & 5 & 15 \\
\hline
\end{tabular}

an assumed virtual truth computed by the well known RTM 6SV1.1. It accounts for polarisation and uses the SOS method as well as aerosol phase matrices based on LorenzMie scattering theory (Vermote et al., 1997). It was validated and found to be consistent to within $1 \%$ when compared to other RTMs by Kotchenova et al. (2006). We use the default accuracy mode of $6 \mathrm{~S}$ with 48 Gaussian scattering angles and 26 atmospheric layers. The use of more calculation angles and layers would be possible, but the accuracy increase would be $0.4 \%$ at best (Kotchenova et al., 2006) and therefore is negligible for our study. The two layers of SMART were chosen to interface at $2 \mathrm{~km}$ above the surface. The lower layer includes dry water soluble aerosols and molecules distributed along the exponential vertical air pressure gradient. The corresponding aerosol optical parameters $g_{\lambda}^{\text {aer }}, \omega_{\lambda}^{\text {aer }}$ and $\alpha_{\lambda}$ are taken from d'Almeida et al. (1991) for SMART and 6S. All results in this study are calculated with identical input parameters in SMART and in $6 \mathrm{~S}$, which are provided in Table 2.

In the following, the accuracy of SMART is investigated for specific approximation uncertainties, as well as for the overall accuracy. As an indicator of the accuracy, we calculate the relative difference or percent error of the reflectance function to the benchmark $6 \mathrm{~S}$ :

$\delta R \cdot 100=\frac{R_{\mathrm{SMART}}^{\mathrm{S}}-R_{6 \mathrm{~S}}^{\mathrm{S}}}{R_{6 \mathrm{~S}}^{\mathrm{S}}} \cdot 100$.

\subsection{Rayleigh scattering approximation and polarisation}

The total Rayleigh scattering is $R_{\lambda}^{\mathrm{mlc}}=R_{\lambda}^{\mathrm{mlcI}}+R_{\lambda}^{\mathrm{mlcII}}$ as given by Eqs. (13) and (14). The associated approximations include the Rayleigh scattering phase function (Eq. 10), the multiple scattering correction factor from MODTRAN (Eq. 12) and the neglected polarisation due to the scalar equations. The percent error is a distinct function of the wavelength and SZA, induced mainly by polarisation. Figure $2 \mathrm{a}$ shows that it grows towards shorter wavelengths and larger

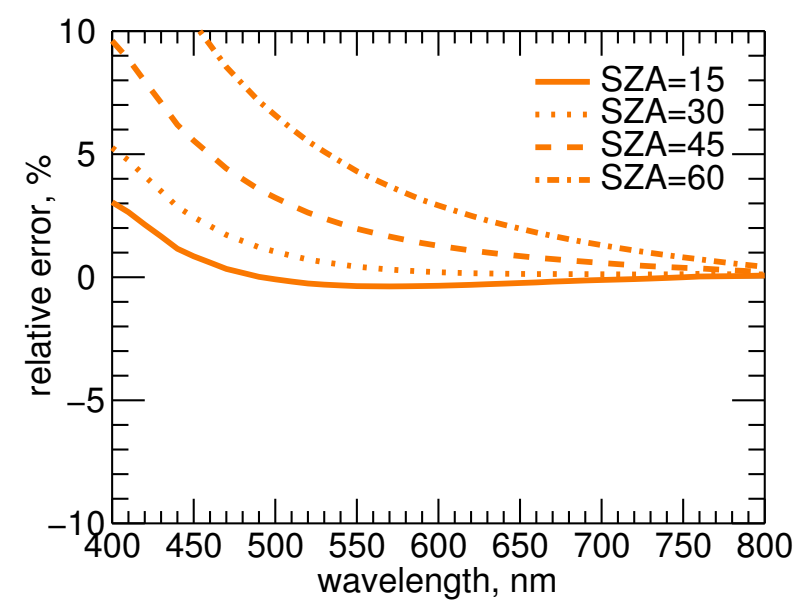

(a) $\delta R_{\lambda}^{\mathrm{mlc}}(\lambda) \cdot 100$

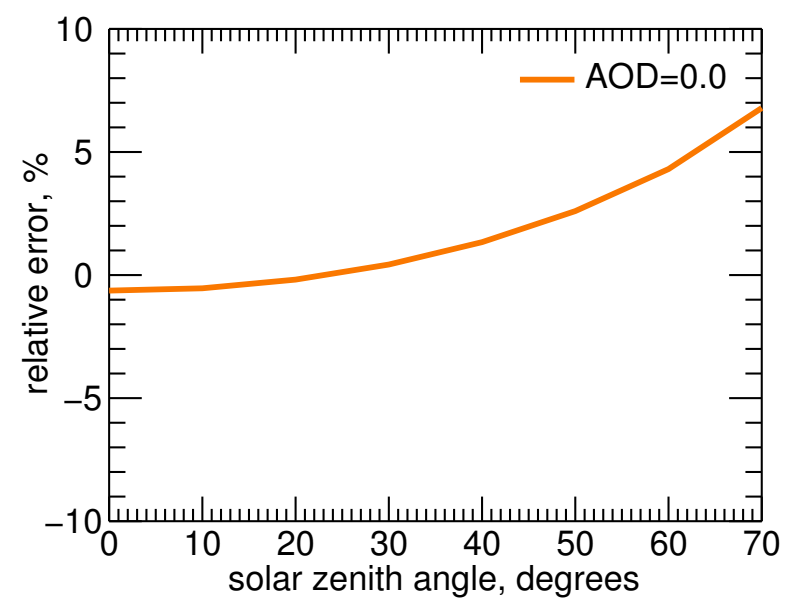

(b) $\delta R_{550 \mathrm{~mm}}^{\mathrm{mlc}}(\mathrm{SZA}) \cdot 100$ at $\lambda=550 \mathrm{~nm}$

Fig. 2. Percent error due to Rayleigh scattering and polarisation with respect to wavelength and solar zenith angle (SZA) at top-ofatmosphere.

SZA. It is known that the scalar approximation can introduce uncertainties of up to $10 \%$ in the blue spectral region (van de Hulst, 1980; Mishchenko et al., 1994). The SZA dependency of this uncertainty is shown in Fig. 2b. At $550 \mathrm{~nm}$, the Rayleigh scattering uncertainty in the typical SZA range from $20-50^{\circ}$ is below $3 \%$.

\subsection{Aerosol scattering approximation}

The main approximations for the aerosol scattering are the double scattering (Eq. 16) and the HG phase function (Eq. 15). Initially, we use the exactly same phase function as in $6 \mathrm{~S}$ in order to study the error induced only by the neglected higher orders of scattering. This phase function for dry water soluble aerosols was derived from the Lorenz-Mie scattering theory. Subsequently, we compare the combined 
Table 2. Summary of the input parameters used in SMART and 6S for the accuracy assessment, with the aerosol and molecular optical depth $\tau_{550 \mathrm{~nm}}^{\mathrm{aer}}$ and $\tau_{550 \mathrm{~nm}}^{\mathrm{mlc}}$, the solar and viewing zenith angle SZA and VZA, the aerosol asymmetry factor and single scattering albedo $g_{550 \mathrm{~nm}}^{\text {aer }}$ and $\omega_{550 \mathrm{~nm}}^{\text {aer }}$, the Ångström parameter $\alpha_{550 \mathrm{~nm}}$, the surface albedo $a_{\lambda}$, as well as the air pressure at the surface and the planetary boundary layer $p^{\mathrm{SFC}}$ and $p^{\mathrm{PBL}}$ and the corresponding scaling factor $h^{\mathrm{PBL}}$.

\begin{tabular}{rccccccccccc}
\hline parameter & $\tau_{550 \mathrm{~nm}}^{\mathrm{aer}}$ & $\tau_{550 \mathrm{~nm}}^{\mathrm{mlc}}$ & SZA & VZA & $g_{550 \mathrm{~nm}}^{\mathrm{aer}}$ & $\omega_{550 \mathrm{~nm}}^{\mathrm{aer}}$ & $\alpha_{550 \mathrm{~nm}}$ & $a_{\lambda}$ & $p^{\mathrm{SFC}}$ & $p^{\mathrm{PBL}}$ & $h^{\mathrm{PBL}}$ \\
\hline value & $0-0.5$ & 0.097 & nadir-70 & nadir & 0.638 & 0.963 & 1.23 & 0 & $1013 \mathrm{mb}$ & $800 \mathrm{mb}$ & 0.211 \\
\hline
\end{tabular}

effect of the double scattering and the HG phase function approximation with $6 \mathrm{~S}$.

The percent error introduced by the double scattering approximation is plotted in Fig. 3. It is almost constant over the spectra due to the higher reflectance at shorter wavelengths (see Fig. 3a). It is obvious that the reflectance function $R_{\lambda}^{\mathrm{S}}$ is increasingly underestimated by SMART for larger AOD due to the neglected third and higher orders of aerosol scattering (see Fig. 3b). Figure 3c shows that larger SZA leads to an underestimation of the atmospheric reflectance for the same reason.

In order to study the accuracy of the total aerosol scattering $R_{\lambda}^{\text {aer }}$ as part of Eq. (14), we include the approximative HG phase function in SMART. 6S still uses the same Mie phase function as before. The input parameter for the HG phase function $g_{\lambda}^{\text {aer }}$ corresponds to the same dry water soluble aerosol, which is used in 6S. The exact Mie and the approximative HG phase function are shown in Fig. 1 for the same aerosol. The latter provides a reasonable approximation for scattering angles around $130^{\circ}$, which corresponds to a $50^{\circ} \mathrm{SZA}$ for nadir observations. The resulting combination of the aerosol double scattering error with the HG approximation error is examined in Fig. 4. It suggests that the use of the HG approximation does not introduce large percent errors within the range of typical SZA, as defined in Table 1. Given a range of $20-45^{\circ}$ SZA, SMART is quite accurate at all investigated wavelengths and AOD values.

By comparing Figs. $3 a$ with $4 a$ and Figs. $3 b$ with $4 b$, it can be seen that the HG approximation reverses some of the errors due to the aerosol double scattering approximation. The HG phase function for dry water soluble aerosols tends to overestimate of the aerosol scattering, which finally leads to a less distinct underestimation due to the neglected third and higher orders of aerosol scattering.

\subsection{Coupling of Rayleigh and aerosol scattering}

The current version of SMART does not yet account for the scattering interaction between molecules and aerosols. We analyse this effect by comparing $6 \mathrm{~S}$ computations with the coupling switched on and off. The relative error related to this specific approximation is shown in Fig. 5. It remains within about $3 \%$, reaching a maximum at large SZA (see Fig. 5c) and short wavelengths (see Fig. 5a). With errors of less than $2 \%$, small SZAs are almost not influenced by the coupling and there is no distinct dependency on AOD noticeable (see Fig. 5b).

\subsection{Overall accuracy}

Previous Sects. 3.1-3.3 demonstrated that the approximations in SMART are adequate. Most of them are within the desired accuracy range of $\pm 5 \%$ for the limited remote sensing conditions as defined in Table 1. Errors of up to $\pm 15 \%$ are found for large SZA, however, they are mainly related to SMART's simple two-layer atmospheric structure.

In the following, we examine the overall accuracy of SMART by comparing it according to Eq. (26) with independent computations of $6 \mathrm{~S}$. The computations of SMART are performed by Eq. (22) for a TOA sensor altitude at $80 \mathrm{~km}$ and by Eq. (23) for an airborne sensor altitude at $5500 \mathrm{~m}$ a.s.l. The percent error due to the excluded coupling between molecules and aerosols is inherent in the results of this subsection.

Figure 6 shows the result of two independent calculations using SMART (solid line) and 6S (dashed line) with respect to $\lambda$ and $\tau_{550 \mathrm{~nm}}^{\text {aer }}$. The qualitative agreement between the two models is evident. A quantitative perspective by statistical means of the overall accuracy is provided in Table 3, where

$R^{2}=1-\frac{\sum\left(R_{\mathrm{SMART}}^{\mathrm{S}}-R_{6 \mathrm{~S}}^{\mathrm{S}}\right)^{2}}{\sum\left(R_{6 \mathrm{~S}}^{\mathrm{S}}-\bar{R}_{6 \mathrm{~S}}\right)^{2}}$

is the squared correlation coefficient between the two models,

$\mathrm{RMSE}=\sqrt{\frac{1}{N} \sum\left(R_{\mathrm{SMART}}^{\mathrm{S}}-R_{6 \mathrm{~S}}^{\mathrm{S}}\right)^{2}}$,

is the root mean square error and

$\mathrm{NRMSE}=\frac{\mathrm{RMSE} \cdot 100}{\max \left(R_{\mathrm{SMART}}^{\mathrm{S}}\right)-\min \left(R_{\mathrm{SMART}}^{\mathrm{S}}\right)}$,

is the normalised RMSE. The statistics are derived from all combinations of input parameters defined in Tables 1 and 2 within the limited conditions. The resulting correlation between SMART and 6S is almost perfect. The RMSE is approximately 0.16 reflectance values and the NRMSE is between $1.8 \%$ and $3.5 \%$. The differences are smaller at TOA in comparison to those at $5500 \mathrm{~m}$. 


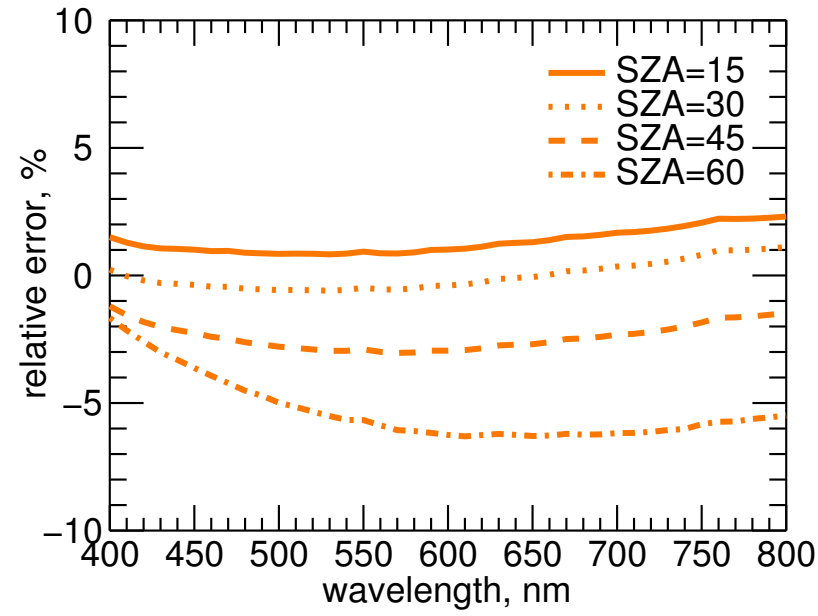

(a) $\delta R^{\text {aer }}$ Mie $(\lambda) \cdot 100$ at $\tau_{550 \mathrm{~nm}}^{\text {aer }}=0.2$

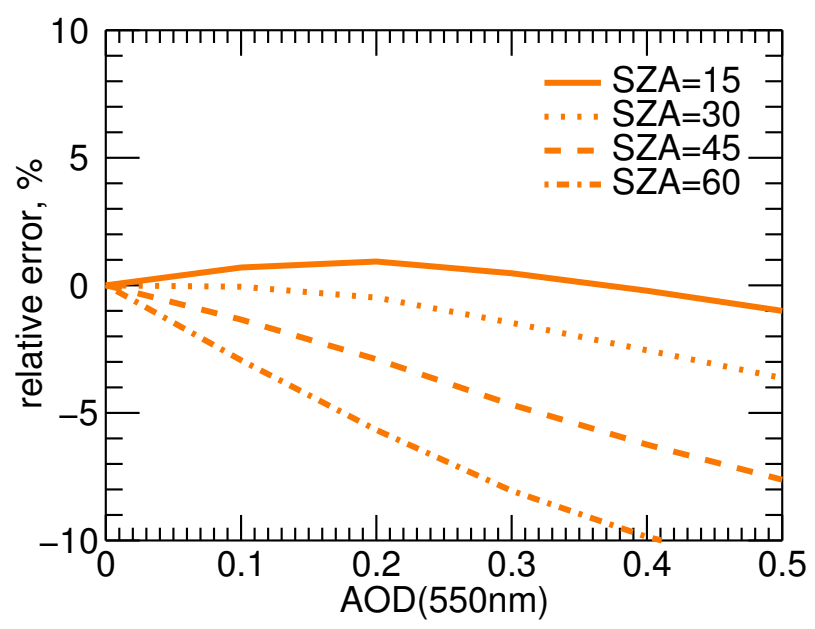

(b) $\left.\delta R_{550 \mathrm{~nm}}^{\text {aer }} \tau_{550 \mathrm{~nm}}^{\text {aer }}\right) \cdot 100$ at $\lambda=550 \mathrm{~nm}$

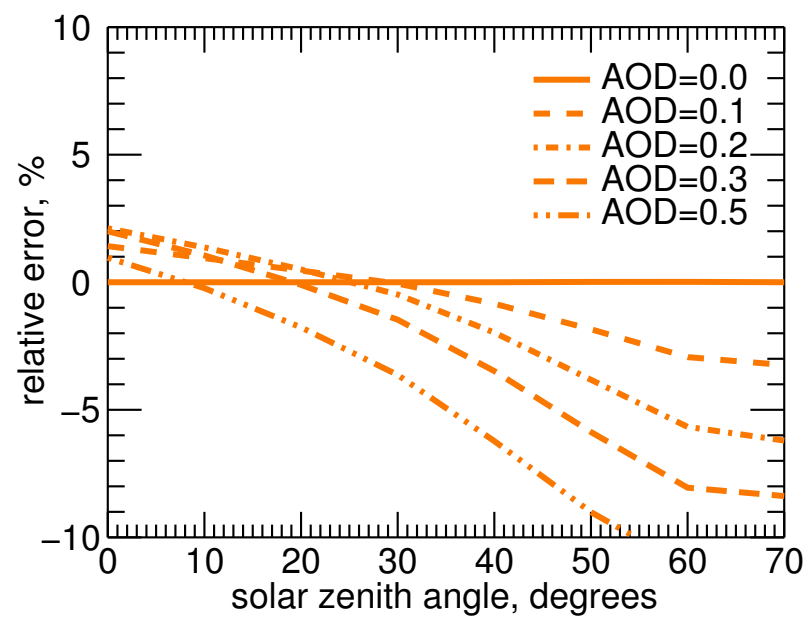

(c) $\delta R_{550 \mathrm{~nm}}^{\mathrm{aer}}(\mathrm{SZA}) \cdot 100$ at $\lambda=550 \mathrm{~nm}$

Fig. 3. Percent error of the SMART reflectance function due to aerosol scattering with respect to wavelength, aerosol optical depth (AOD) and solar zenith angle (SZA) at top-of-atmosphere. SMART and $6 \mathrm{~S}$ use the same phase function from Lorenz-Mie theory.

www.atmos-meas-tech.net/3/1129/2010/

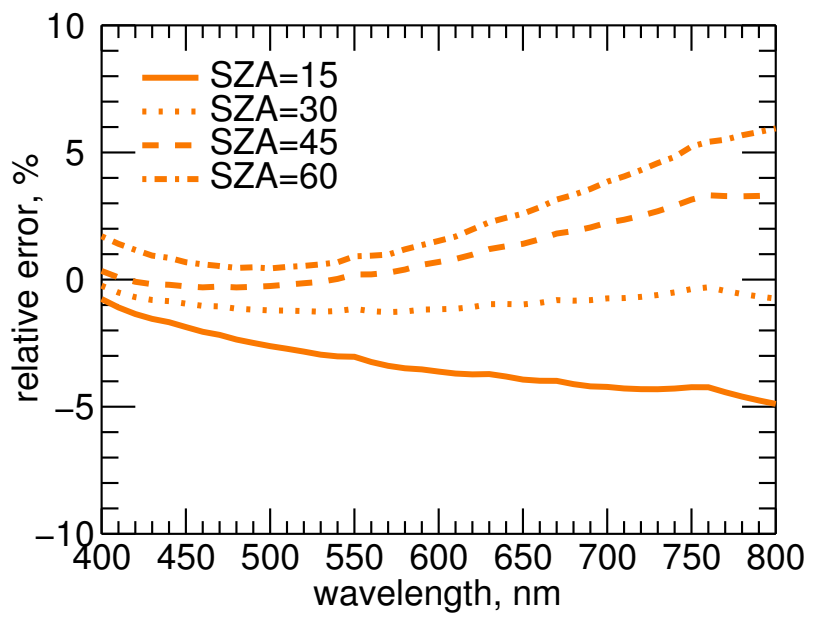

(a) $\delta R^{\text {aer }}{ }_{\mathrm{HG}}(\lambda) \cdot 100$ at $\tau_{550 \mathrm{~nm}}^{\text {aer }}=0.2$

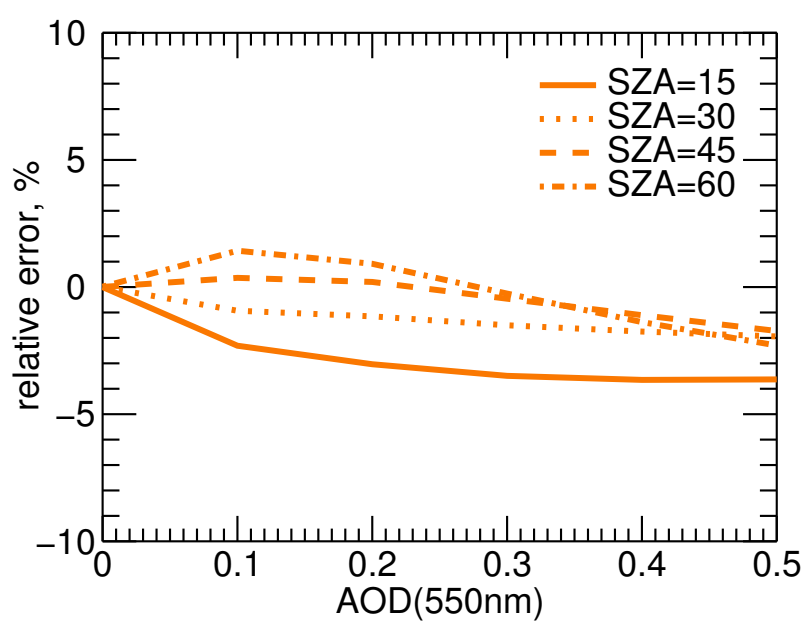

(b) $\delta R_{550 \mathrm{~nm}}^{\mathrm{aer}}\left(\tau_{550 \mathrm{~nm}}^{\mathrm{aer}}\right) \cdot 100$ at $\lambda=550 \mathrm{~nm}$

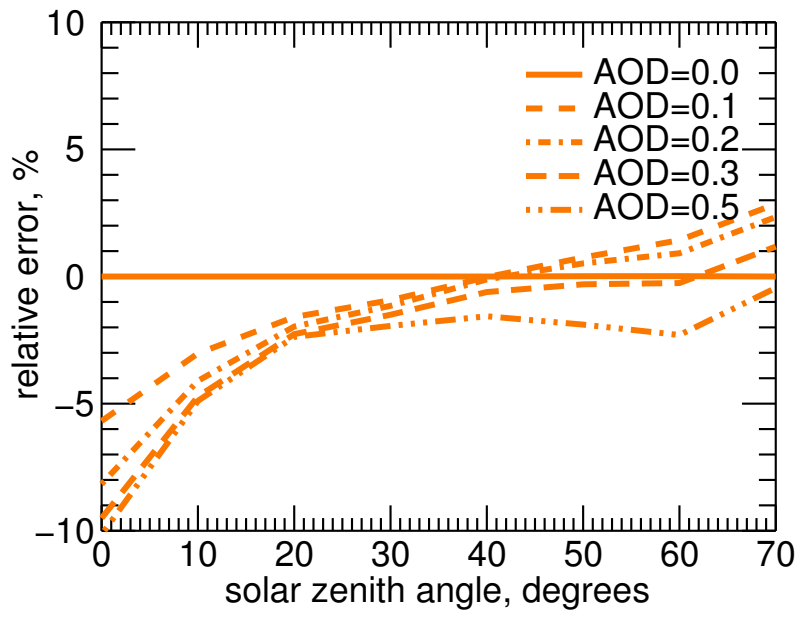

(c) $\delta R_{550 \mathrm{~nm}}^{\mathrm{aer}}(\mathrm{SZA}) \cdot 100$ at $\lambda=550 \mathrm{~nm}$

Fig. 4. Percent error of the SMART reflectance function due to aerosol scattering with respect to wavelength, aerosol optical depth (AOD) and solar zenith angle (SZA) at top-of-atmosphere. SMART uses the HG phase function, $6 \mathrm{~S}$ the phase function from Lorenz-Mie theory.

Atmos. Meas. Tech., 3, 1129-1141, 2010 


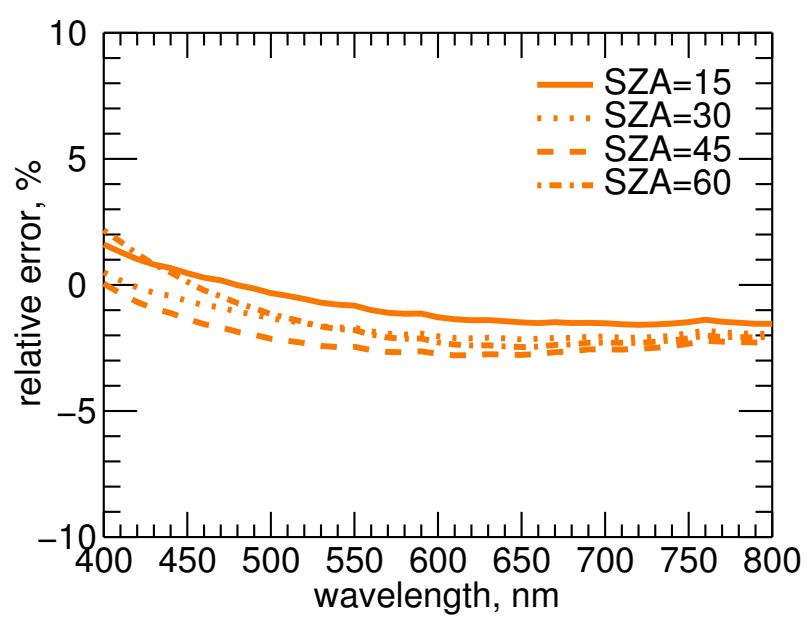

(a) $\delta R^{\mathrm{mlc}+\text { aer }}(\lambda) \cdot 100$ at $\tau_{550 \mathrm{~nm}}^{\text {aer }}=0.3$

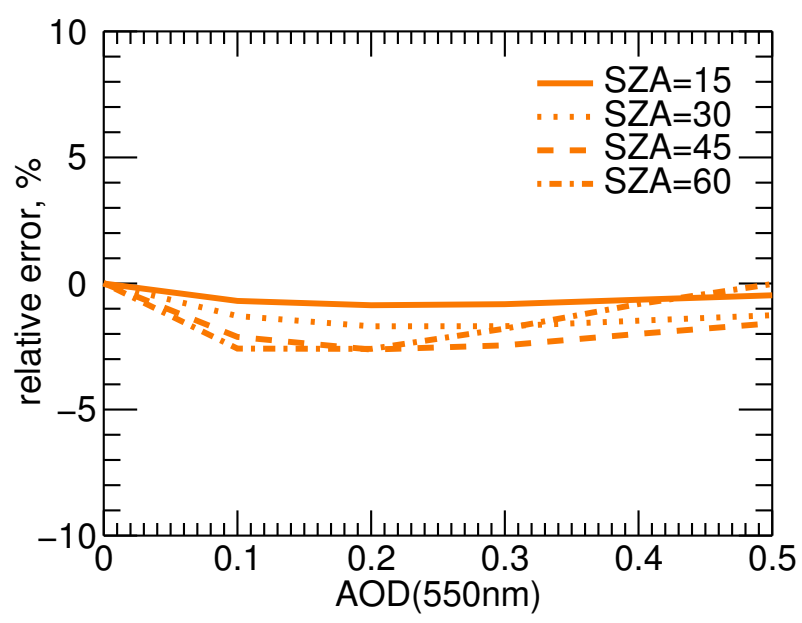

(b) $\delta R_{550 \mathrm{~nm}}^{\mathrm{mlc}+\text { aer }}\left(\tau_{550 \mathrm{~nm}}^{\mathrm{aer}}\right) \cdot 100$ at $\lambda=550 \mathrm{~nm}$

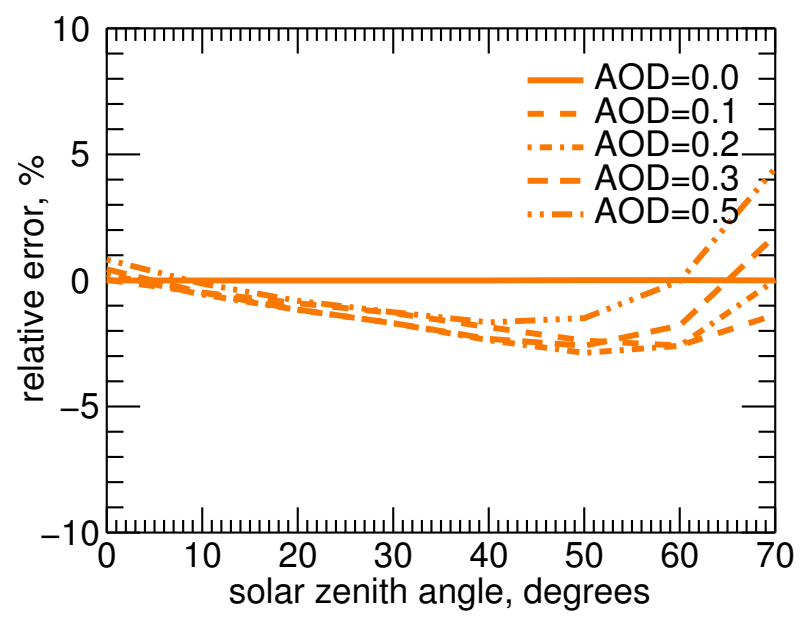

(c) $\delta R_{550 \mathrm{~nm}}^{\mathrm{mlc}+\mathrm{aer}}(\mathrm{SZA}) \cdot 100$ at $\lambda=550 \mathrm{~nm}$

Fig. 5. Percent error due to the non-coupling approximation with respect to wavelength, aerosol optical depth (AOD) and solar zenith angle (SZA) at top-of-atmosphere.

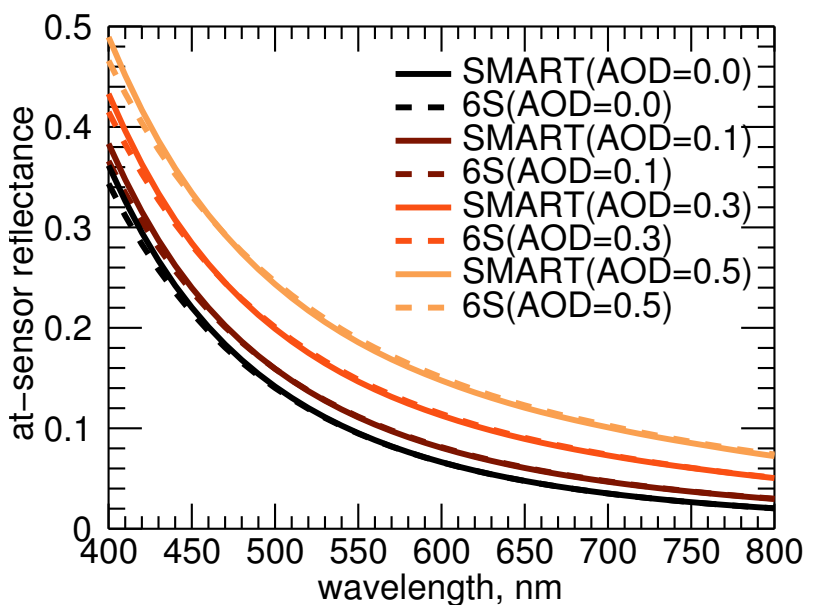

Fig. 6. Results of the at-sensor reflectance function $R_{\lambda}^{\mathrm{S}, \mathrm{TOA}}$ (Eq. 22) computed by SMART (solid line) and 6S (dashed line) at TOA, SZA $=30^{\circ}$ and varying $\tau_{550 \mathrm{~nm}}^{\mathrm{aer}}$. SMART uses the HG phase function, while $6 \mathrm{~S}$ uses the phase function from Mie theory. Remaining input parameters are given in Table 2 .

In the following, we analyse the overall accuracy of Eq. (22) by Eq. (26) in more details with respect to wavelength, SZA and AOD. SMART computes very similar results compared to $6 \mathrm{~S}$ at TOA with an SZA between $30^{\circ}$ and $40^{\circ}$. This conclusion can be drawn from the combination of Figs. $2 b, 4 c$ and $5 c$, as well as from the total percent error in Fig. 7a. The overall percent error does not exceed $\pm 5 \%$ at any investigated wavelength or AOD. At the large SZA of $60^{\circ}$, SMART overestimates $R_{\lambda}^{\mathrm{S}, \mathrm{TOA}}$ by more than $10 \%$ at short wavelengths. Nevertheless, the overall accuracy is still well within the acceptable range of $10 \%$ at any wavelength larger than $450 \mathrm{~nm}$ (see Fig. 7b). At $550 \mathrm{~nm}$, only the combination of very small SZA with a strong AOD or a high SZA with low AOD leads to a percent error just outside of the desired 5\% margin (see Fig. 7c). In the blue part of the spectrum, high or low SZA lead to significant percent errors in a pure Rayleigh scattering atmosphere (see Fig. 7e). The same is true in an atmosphere containing aerosols, where the aerosols introduce additional percent errors in the red part of the spectrum for small SZAs (see Fig. 7d and f).

Since SMART is also intended for the use with airborne remote sensing data, we additionally analyse the overall accuracy of Eq. (23) by Eq. (26). We place the sensor at $5500 \mathrm{~m}$ above the assumed black surface at sea level. The airborne scenario is more sensitive to the approximative two-layer setup in SMART. The 26 atmospheric layers in $6 \mathrm{~S}$ can better account for the vertically inhomogeneous atmosphere. In fact, the percent error is slightly larger in the airborne case in comparison with the TOA case. The error distribution in the contour plots of Fig. 8a-f show that SMART underestimates the reflectance factors at $5500 \mathrm{~m}$. Nevertheless, the hypothetical pure Rayleigh atmosphere still performs well, 


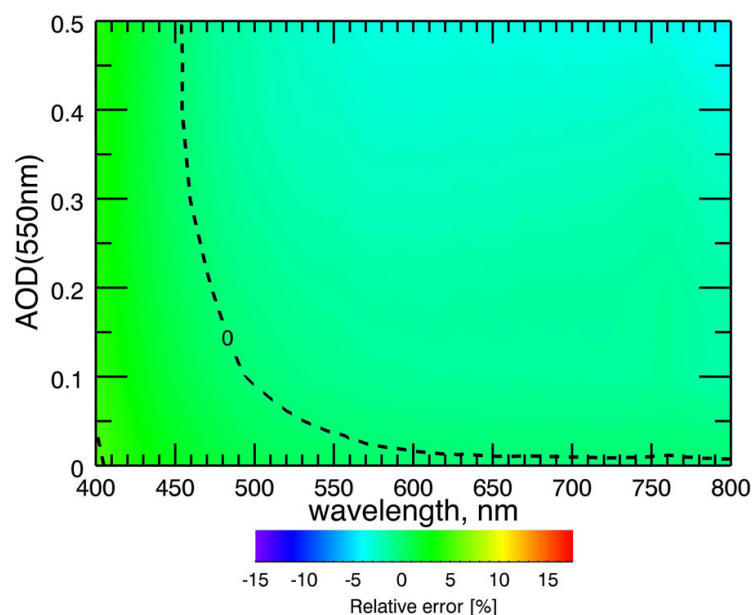

(a) $\delta R^{\mathrm{S}, \mathrm{TOA}}\left(\lambda, \tau_{550 \mathrm{~nm}}^{\mathrm{aer}}\right) \cdot 100$ at $30^{\circ} \mathrm{SZA}$

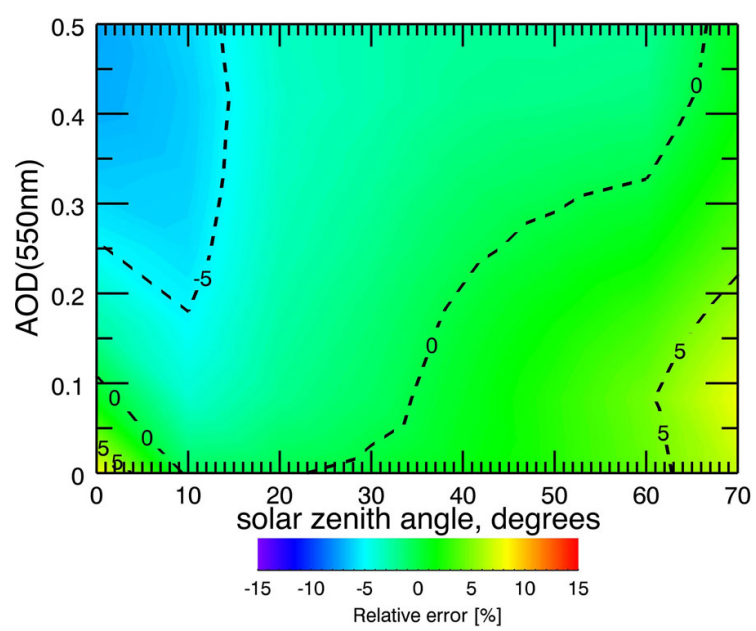

(c) $\delta R_{550 \mathrm{~nm}}^{\mathrm{S}, \mathrm{TOA}}\left(\mathrm{SZA}, \tau_{550 \mathrm{~nm}}^{\mathrm{aer}}\right) \cdot 100$ at $\lambda=550 \mathrm{~nm}$

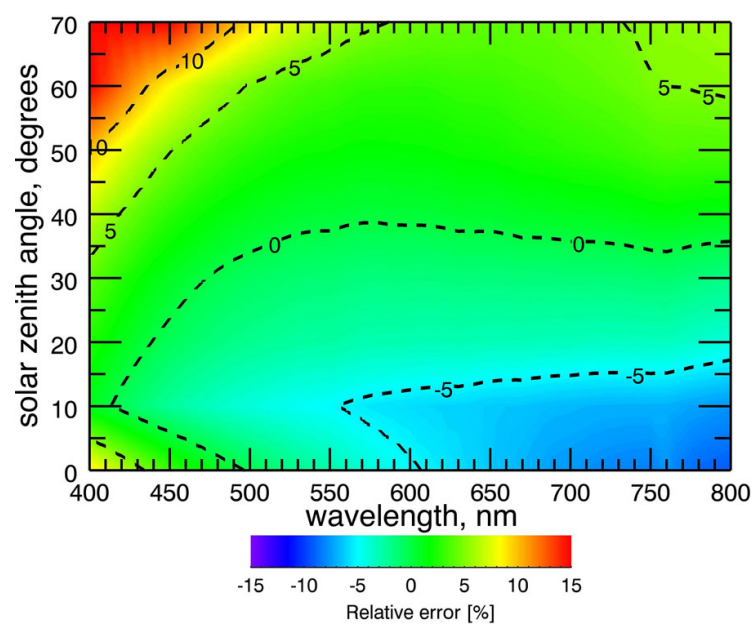

(e) $\delta R^{\mathrm{S}, \mathrm{TOA}}(\lambda, \mathrm{SZA}) \cdot 100$ at $\tau_{550 \mathrm{~nm}}^{\text {aer }}=0.2$

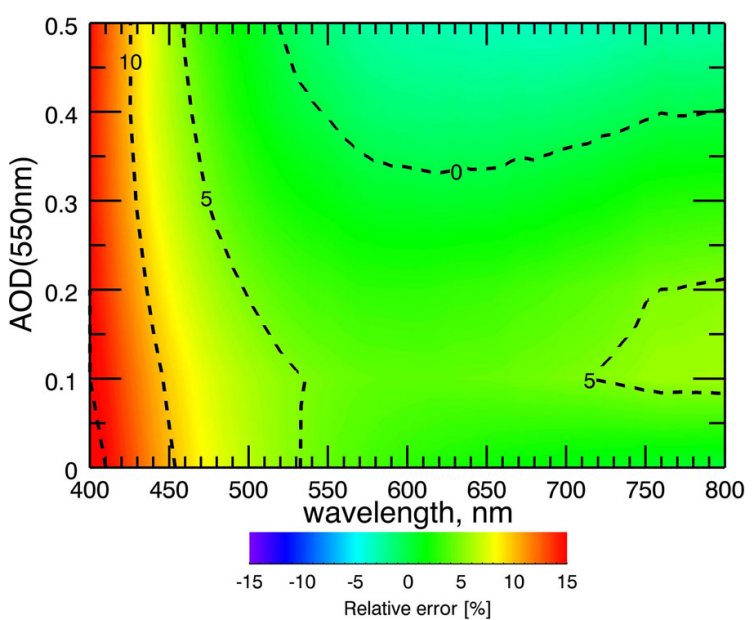

(b) $\delta R^{\mathrm{S}, \mathrm{TOA}}\left(\lambda, \tau_{550 \mathrm{~nm}}^{\mathrm{aer}}\right) \cdot 100$ at $60^{\circ} \mathrm{SZA}$

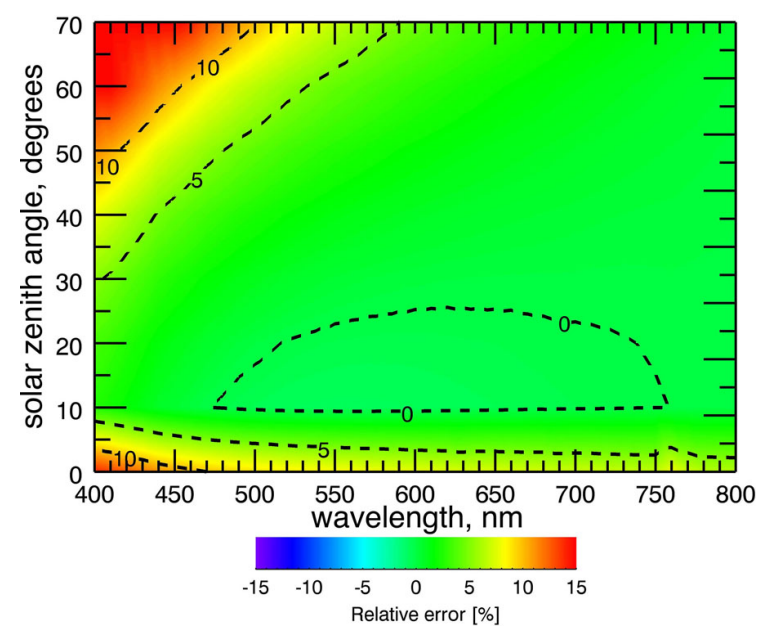

(d) $\delta R^{\mathrm{S}, \mathrm{TOA}}(\lambda, \mathrm{SZA}) \cdot 100$ at $\tau_{550 \mathrm{~nm}}^{\text {aer }}=0.0$

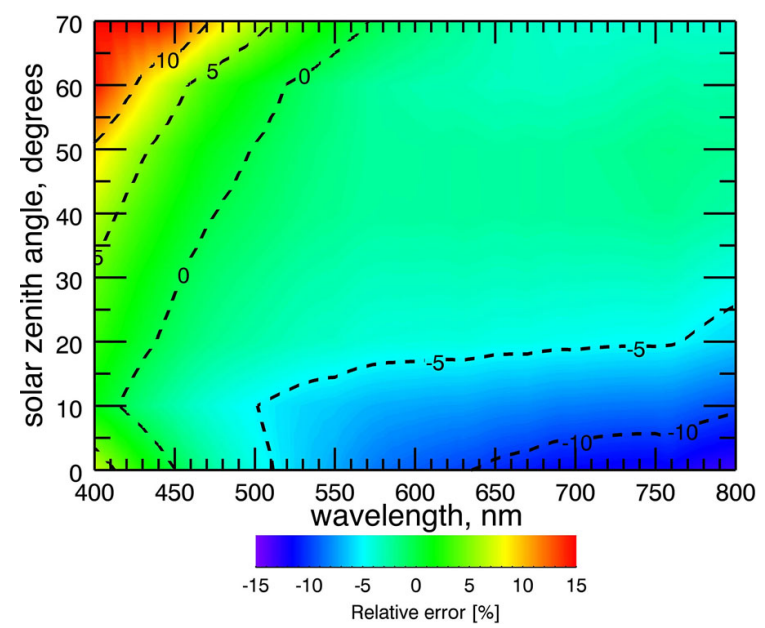

(f) $\delta R^{\mathrm{S}, \mathrm{TOA}}(\lambda, \mathrm{SZA}) \cdot 100$ at $\tau_{550 \mathrm{~nm}}^{\text {aer }}=0.5$

Fig. 7. Overall accuracy with a sensor at top-of-atmosphere. 
Table 3. Quantitative comparison between SMART and $6 \mathrm{~S}$ by statistical means for the limited conditions as defined in Table 1. SMART uses the HG phase function; $6 \mathrm{~S}$ used the phase function from Mie calculations. $R^{2}$ denotes the squared correlation coefficient, RMSE the root mean square error and NRMSE the normalised RMSE.

\begin{tabular}{lccc}
\hline sensor altitude & $R^{2}$ & RMSE & NRMSE \\
\hline TOA & 0.998 & 0.157 & $1.77 \%$ \\
$5500 \mathrm{~m}$ & 0.998 & 0.167 & $3.52 \%$ \\
\hline
\end{tabular}

with a maximum percent error of $6 \%$ (see Fig. 8a, b and c). The aerosols worsen the underestimation in the lower half of the visible spectrum, especially at very small and very large SZAs. At $550 \mathrm{~nm}$ and a $30^{\circ} \mathrm{SZA}$, the percent error is $6 \%$ or less for an AOD up to 0.5. With the same constellation but an extreme SZA, the percent errors reach about $10 \%$ (see Fig. 8c, e and f). The largest offset between SMART and 6S is found at $60^{\circ} \mathrm{SZA}, 400 \mathrm{~nm}$ and an AOD of 0.5 with $18 \%$ relative difference. However, it should be noted that absolute difference $R_{\mathrm{SMART}}^{\mathrm{S}}-R_{6 \mathrm{~S}}^{\mathrm{S}}$ is in fact smaller in the airborne case compared to the TOA case (not shown). Nonetheless, the relative error given by Eq. (26) is larger due to the smaller $R_{6 \mathrm{~S}}^{\mathrm{S}}$ in the denominator.

\section{Performance assessment}

SMART is designed to optimally balance the opposing needs for accuracy and computational speed; the speed decreases with increasing model complexity and accuracy. We use the $6 \mathrm{~S}$ vector version 1.1 (Vermote et al., 1997) as a benchmark RTM (same as in Sect. 3) to assesses the performance of SMART. 6S is compiled with GNU Fortran and SMART is implemented in IDL. Both run on the same CPU infrastructure.

SMART needs only approximately $0.05 \mathrm{~s}$ for the calculation of one reflectance factor value. The more complex $6 \mathrm{~S}$ needs about $1.4 \mathrm{~s}$ under identical conditions. Consequently, SMART computes more than 25 times faster. If $R_{\lambda}^{\text {aer,MS }}$ (Eq. 16) is substituted by a simple correction factor $f_{\mu_{0}}^{\text {corr }}(\lambda, \tau)$ for aerosol multiple scattering (similar to Eq. 12), SMART runs 220 times faster than by numerically solving Eq. (16) in the presented configuration.

\section{Summary and conclusions}

We introduced SMART, as well as its approximative radiative transfer equations and parameterizations. Results of the atmospheric at-sensor reflectance function computed by SMART were compared with benchmark results from $6 \mathrm{~S}$ for accuracy and performance. The overall percent error was examined and discussed, as were the individual errors resulting from Rayleigh scattering, aerosol scattering and moleculeaerosol interactions. The aerosol scattering was compared to $6 \mathrm{~S}$ with and without the effect of the HG phase function approximation.

We found that SMART fulfils its design principle: it is fast and simple, yet accurate enough for a range of applications. One example may include the assessment of atmospheric effects when inspecting the quality of airborne or spaceborne data against ground truth measurements in near-real-time. The generation of atmospheric input parameters for vegetation canopy RTM inversion schemes, could be another application. SMART computes more than 20 reflectance results per second on a current customary desktop computer. This is more than 25 times faster than the benchmark RTM. The overall percent error under typical mid-latitude remote sensing conditions was found to be about $5 \%$ for the spaceborne and $5 \%$ to $10 \%$ for the airborne case. Large AOD or SZA values lead to larger percent errors of up to $15 \%$. In general, the included approximations are sensitive to the strong scattering in the blue spectral region, which leads to larger percent errors. Together with the effect of polarisation, the total percent error of SMART exceeds the desired accuracy goal of 5\% only in the blue region. It is therefore suggested that SMART be used preferably in the spectral range between roughly $500 \mathrm{~nm}$ and $680 \mathrm{~nm}$, avoiding the blue and strong absorption bands. However, the neglected ozone absorption in this spectral interval leads to a small overestimation of up to 0.007 reflectance units at large SZA and $600 \mathrm{~nm}$. It is also recommended to use SMART for computations with a sensor above the PBL to avoid uncertainties in the vertical distribution of the aerosols.

SMART can be improved by implementing other phase functions instead of the HG approximation, including those derived from Lorenz-Mie theory, geometrical optics (raytracing), and T-matrix approaches (Liou and Hansen, 1971; Mishchenko et al., 2002). Further refinements may include the coupling between molecules and aerosols, as well as the implementation of freely mixable aerosol components and hygroscopic growth (Hess et al., 1998). To account for polarisation, the scalar equations can be extended to the vector notation. Furthermore, a similar approach as used for the Rayleigh multiple scattering in this study (Eq. 12) may perhaps be used to perform a rough polarisation correction. Other issues for further developments may include additional atmospheric layers, gaseous absorption (foremost ozone), adjacency effects and the treatment of a directional, non-Lambertian surface.

A recent inter-comparison study for classic RTMs such as 6S, RT3, MODTRAN and SHARM, found discrepancies of $\delta R \leq 5 \%$ at TOA (Kotchenova et al., 2008). Even larger errors were found when polarisation was neglected or the HG phase function was used. SMART does not yet account for polarisation and uses the HG approximation by default, however 


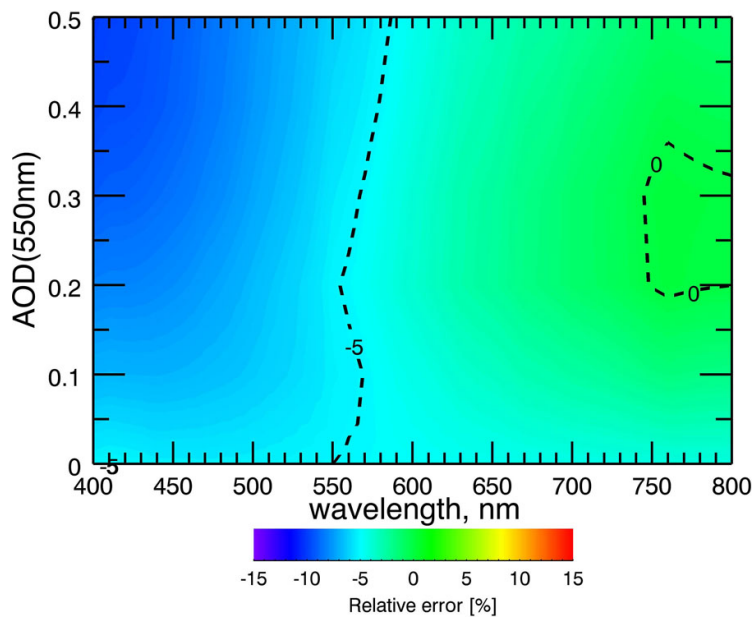

(a) $\delta R^{\mathrm{S}, 5500 \mathrm{~m}}\left(\lambda, \tau_{550 \mathrm{~nm}}^{\text {aer }}\right) \cdot 100$ at $30^{\circ} \mathrm{SZA}$

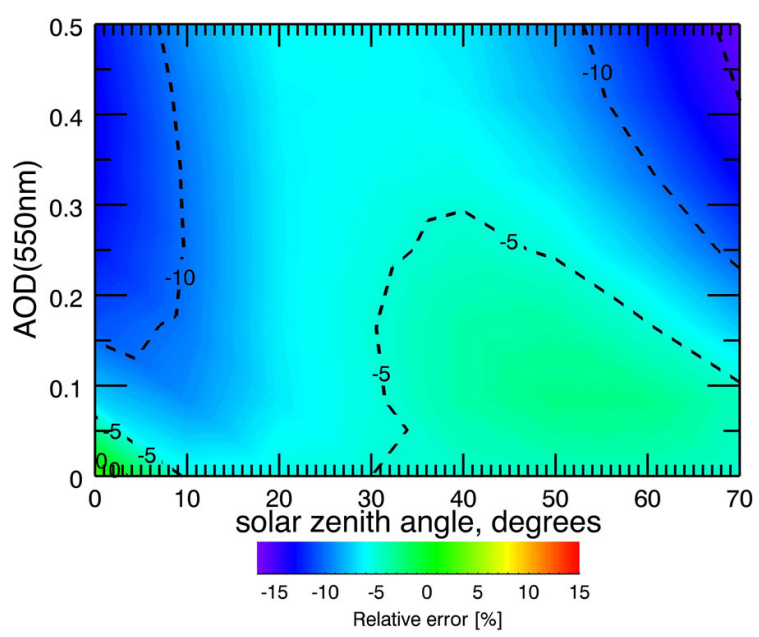

(c) $\delta R_{550 \mathrm{~nm}}^{\mathrm{S}, 5500 \mathrm{~m}}\left(\mathrm{SZA}, \tau_{550 \mathrm{~nm}}^{\mathrm{aer}}\right) \cdot 100$ at $\lambda=550 \mathrm{~nm}$

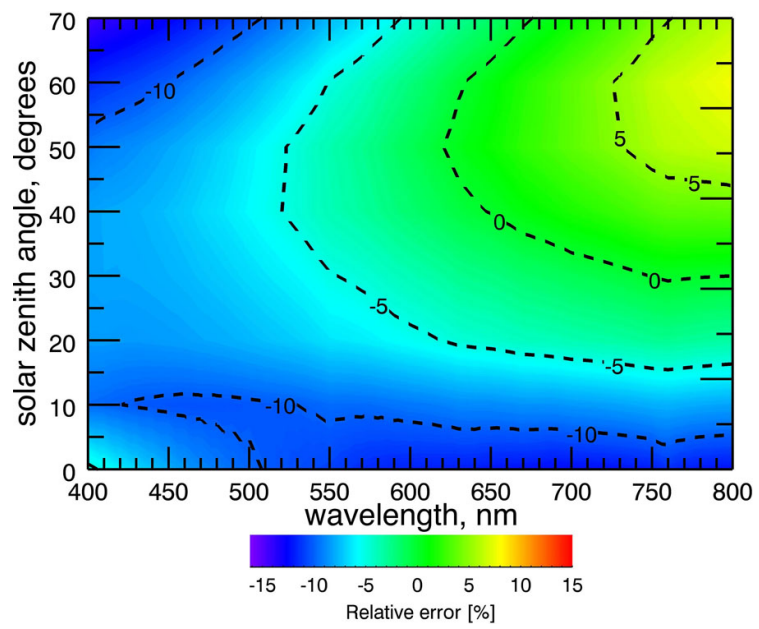

(e) $\delta R^{\mathrm{S}, 5500 \mathrm{~m}}(\lambda, \mathrm{SZA}) \cdot 100$ at $\tau_{550 \mathrm{~nm}}^{\mathrm{aer}}=0.2$

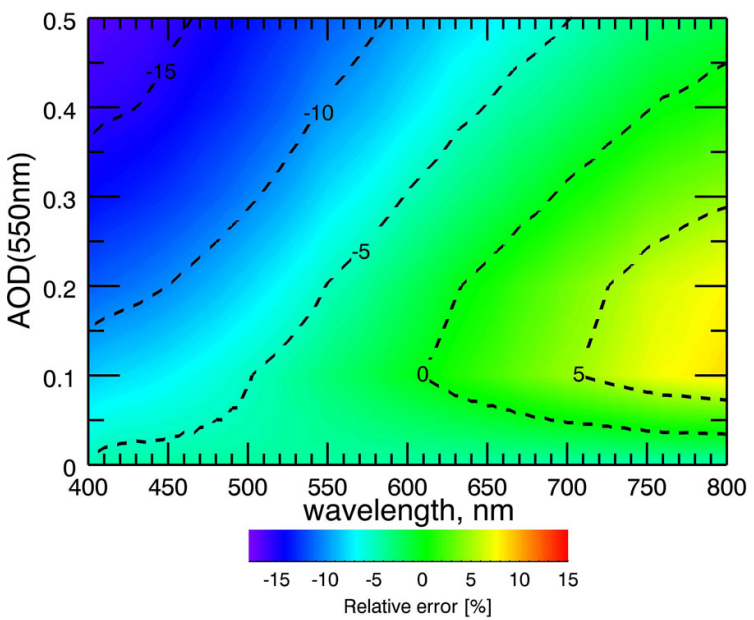

(b) $\delta R^{\mathrm{S}, 5500 \mathrm{~m}}\left(\lambda, \tau_{550 \mathrm{~nm}}^{\text {aer }}\right) \cdot 100$ at $60^{\circ} \mathrm{SZA}$

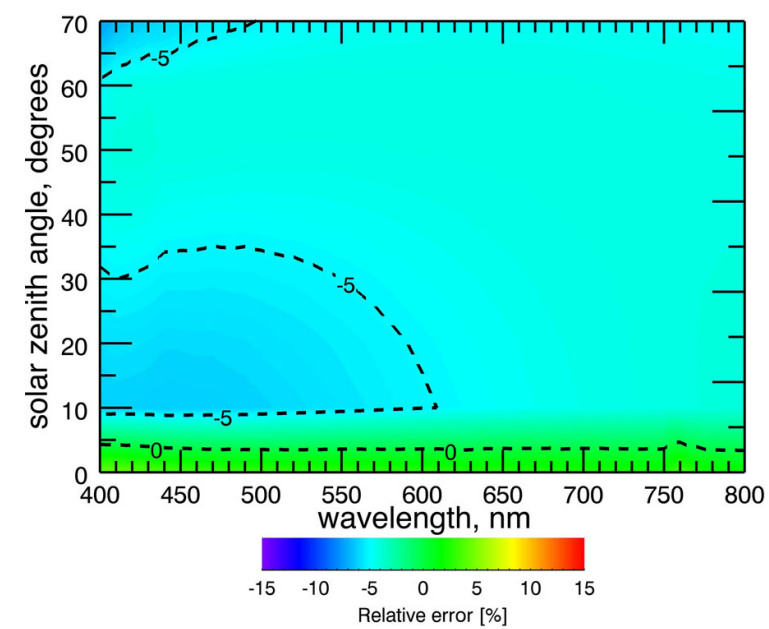

(d) $\delta R^{\mathrm{S}, 5500 \mathrm{~m}}(\lambda, \mathrm{SZA}) \cdot 100$ at $\tau_{550 \mathrm{~nm}}^{\text {aer }}=0$

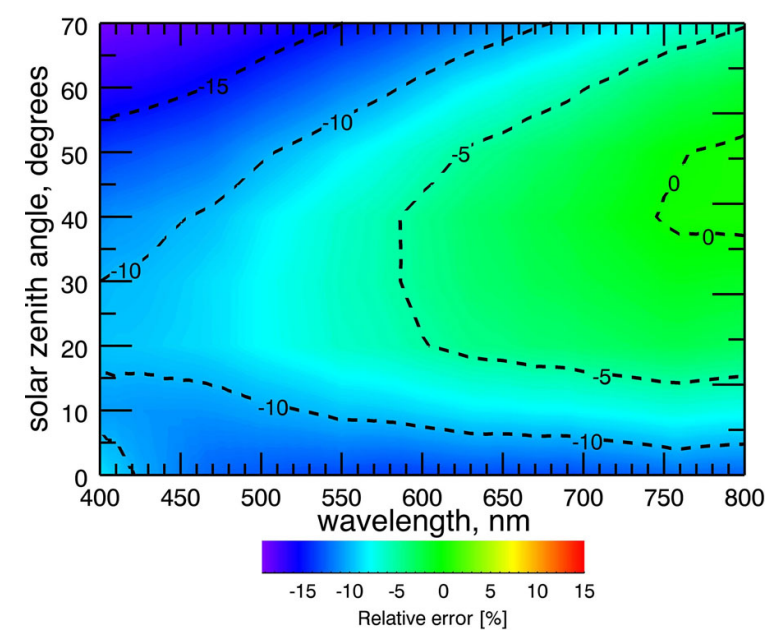

(f) $\delta R^{\mathrm{S}, 5500 \mathrm{~m}}(\lambda, \mathrm{SZA}) \cdot 100$ at $\tau_{550 \mathrm{~nm}}^{\text {aer }}=0.5$

Fig. 8. Overall accuracy with a sensor at $5500 \mathrm{~m}$. 
with the option to include pre-calculated Mie phase functions. Therefore, the overall accuracy achieved by SMART under given conditions can be regarded as satisfactory, especially when a computationally fast RTM is required.

Acknowledgements. The work of A. A. Kokhanovsky was performed in the framework of DFG Project Terra. Suggestions from D. Schlaepfer and A. Schubert were very much appreciated. We thank three anonymous referees for their valuable comments on the AMTD version of this publication.

Edited by: M. Wendisch

\section{References}

Ångström, A.: The albedo of various surfaces of ground, Geogr. Ann., 7, 323-342, available at: http://www.jstor.org/stable/ 519495, last access: 1 May 2010, 1925.

Ångström, A.: On the atmospheric transmission of sun radiation and on dust in the air, Geogr. Ann., 11, 156-166, available at: http://www.jstor.org/stable/519399, last access: 1 May 2010, 1929.

Berk, A., Bernstein, L., and Robertson, D.: MODTRAN: a moderate resolution model for LOWTRAN7, Tech. Rep. GL-TR-890122, Air Force Geophysics Lab, Hanscom AFB, Massachusetts, USA, 1989.

Bodhaine, B. A., Wood, N. B., Dutton, E. G., and Slusser, J. R.: On Rayleigh optical depth calculations, J. Atmos. Ocean. Tech., 16, 1854-1861, doi:10.1175/15200426(1999)016<1854:ORODC> 2.0.CO;2, 1999.

Carrer, D., Roujean, J.-L., Hautecoeur, O., and Elias, T.: Daily estimates of aerosol optical thickness over land surface based on a directional and temporal analysis of SEVIRI MSG visible observations, J. Geophys. Res., 115, D10208, doi:10.1029/2009JD012272, 2010.

Chandrasekhar, S.: Radiative Transfer, Dover, New York, USA, 1960.

d'Almeida, G., Koepke, P., and Shettle, E.: Atmospheric aerosols: global climatology and radiative characteristics, Deepak, Hampton, Virginia, USA, 1991.

Evans, K. F. and Stephens, G. L.: A new polarized atmospheric radiative transfer model, J. Quant. Spectrosc. Ra., 46, 413-423, doi:10.1016/0022-4073(91)90043-P, 1991.

Gao, B.-C., Montes, M. J., Davis, C. O., and Goetz, A. F. H.: Atmospheric correction algorithms for hyperspectral remote sensing data of land and ocean, Remote Sens. Environ., 113, S17-S24, doi:10.1016/j.rse.2007.12.015, 2009.

Govaerts, Y.: RTMOM V0B.10 Evaluation report, report EUM/MET/DOC/06/0502, EUMETSAT, 2006.

Hammad, A. and Chapman, S.: VII. The primary and secondary scattering of sunlight in a plane-stratified atmosphere of uniform composition, Philos. Mag., 28, 99-110, available at: http://articles.adsabs.harvard.edu//full/1948ApJ...108..338H/ 0000338.000.html, last access: 1 May 2010, 1939.

Hansen, J. E. and Travis, L. D.: Light scattering in planetary atmospheres, Space Sci. Rev., 16, 527-610, doi:10.1007/BF00168069, 1974.
Henyey, L. and Greenstein, J.: Diffuse radiation in the galaxy, Astrophys. J., 93, 70-83, available at: http://articles.adsabs.harvard. edu/full/1940AnAp....3..117H, last access: 1 May 2010, 1941.

Hess, M., Koepke, P., and Schult, I.: Optical properties of aerosols and clouds: the software package OPAC, B. Am. Meteorol. Soc., 79, 831-844, 1998.

Itten, K. I., Dell'Endice, F., Hueni, A., Kneubühler, M., Schläpfer, D., Odermatt, D., Seidel, F., Huber, S., Schopfer, J., Kellenberger, T., Bühler, Y., D'Odorico, P., Nieke, J., Alberti, E., and Meuleman, K.: APEX - the hyperspectral ESA airborne prism experiment, Sensors, 8, 6235-6259, doi:10.3390/s8106235, available at: http://www.mdpi.com/1424-8220/8/10/6235, last access: 1 May 2010, 2008.

Katsev, I. L., Prikhach, A. S., Zege, E. P., Grudo, J. O., and Kokhanovsky, A. A.: Speeding up the AOT retrieval procedure using RTT analytical solutions: FAR code, Atmos. Meas. Tech. Discuss., 3, 1645-1705, doi:10.5194/amtd-3-1645-2010, 2010.

Key, J. and Schweiger, A.: Tools for atmospheric radiative transfer: Streamer and FluxNet, Comput. Geosci., 24, 443-451, doi:10.1016/S0098-3004(97)00130-1, 1998.

Kokhanovsky, A. A.: Cloud optics, Springer, Berlin, Germany, 276 pp., 2006.

Kokhanovsky, A. A.: Aerosol optics - Light Absorption and Scattering by Particles in the Atmosphere, Springer Praxis Books, Springer Berlin Heidelberg, 148 pp., 2008.

Kokhanovsky, A. A., Deuzé, J. L., Diner, D. J., Dubovik, O., Ducos, F., Emde, C., Garay, M. J., Grainger, R. G., Heckel, A., Herman, M., Katsev, I. L., Keller, J., Levy, R., North, P. R. J., Prikhach, A. S., Rozanov, V. V., Sayer, A. M., Ota, Y., Tanré, D., Thomas, G. E., and Zege, E. P.: The inter-comparison of major satellite aerosol retrieval algorithms using simulated intensity and polarization characteristics of reflected light, Atmos. Meas. Tech., 3, 909-932, doi:10.5194/amt-3-909-2010, 2010.

Kokhanovsky, A. A. and de Leeuw, G.: Satellite aerosol remote sensing over land, Environmental Sciences, Springer Praxis Books, 388 pp., 2009.

Kokhanovsky, A. A., Mayer, B., and Rozanov, V. V.: A parameterization of the diffuse transmittance and reflectance for aerosol remote sensing problems, Atmos. Res., 73, 37-43, doi:10.1016/j.atmosres.2004.07.004, 2005.

Kotchenova, S. Y., Vermote, E. F., Levy, R., and Lyapustin, A.: Radiative transfer codes for atmospheric correction and aerosol retrieval: intercomparison study, Appl. Optics, 47, 2215-2226, doi:10.1364/AO.47.002215, 2008.

Kotchenova, S. Y., Vermote, E. F., Matarrese, R., and Klemm, F. J.: Validation of a vector version of the $6 \mathrm{~S}$ radiative transfer code for atmospheric correction of satellite data. Part I: Path radiance, Appl. Optics, 45, 6762-6774, doi:10.1364/AO.45.006762, 2006.

Liou, K. and Hansen, J.: Intensity and polarization for single scattering by polydisperse sphere: A comparison of ray optics and Mie theory, J. Atmos. Sci., 28, 995-1004, doi:10.1175/15200469(1971)028<0995:IAPFSS > 2.0.CO;2, 1971.

Lyapustin, A. I.: Radiative transfer code SHARM for atmospheric and terrestrial applications, Appl. Optics, 44, 7764-7772, doi:10.1364/AO.44.007764, 2005.

Mishchenko, M. I., Lacis, A. A., and Travis, L. D.: Errors induced by the neglect of polarization in radiance calculations for rayleigh-scattering atmospheres, J. Quant. Spectrosc. Ra., 51, 491-510, doi:10.1016/0022-4073(94)90149-X, 1994. 
Mishchenko, M. I., Travis, L. D., and Lacis, A. A.: Scattering, absorption, and emission of light by small particles, Cambridge University Press, Cambridge, doi:10.1016/S00224073(98)00025-9, 2002.

Muldashev, T. Z., Lyapustin, A. I., and Sultangazin, U. M.: Spherical harmonics method in the problem of radiative transfer in the atmosphere-surface system, J. Quant. Spectrosc. Ra., 61, 393404, doi:10.1016/S0022-4073(98)00025-9, 1999.

Nakajima, T. and Tanaka, M.: Matrix formulations for the transfer of solar radiation in a plane-parallel scattering atmosphere, J. Quant. Spectrosc. Ra., 35, 13-21, doi:10.1016/00224073(86)90088-9, 1986.

Ota, Y., Higurashi, A., Nakajima, T., and Yokota, T.: Matrix formulations of radiative transfer including the polarization effect in a coupled atmosphere-ocean system, J. Quant. Spectrosc. Ra., 111, 878-894, doi:10.1016/j.jqsrt.2009.11.021, 2010.

Ricchiazzi, P., Yang, S., Gautier, C., and Sowle, D.: SBDART: A research and teaching software tool for plane-parallel radiative transfer in the Earth's atmosphere, B. Am. Meteorol. Soc., 79, 2101-2114, 1998.

Rozanov, A., Rozanov, V., Buchwitz, M., Kokhanovsky, A., and Burrows, J.: SCIATRAN 2.0 - A new radiative transfer model for geophysical applications in the $175-2400 \mathrm{~nm}$ spectral region, Adv. Space Res., 36, 1015-1019, doi:10.1016/j.asr.2005.03.012, 2005.

Ruckstuhl, C., Philipona, R., Behrens, K., Collaud Coen, M., Dürr, B., Heimo, A., Mätzler, C., Nyeki, S., Ohmura, A., Vuilleumier, L., Weller, M., Wehrli, C., and Zelenka, A.: Aerosol and cloud effects on solar brightening and the recent rapid warming, Geophys. Res. Lett., 35, L12708, doi:10.1029/2008GL034228, 2008.

Ruggaber, A., Dlugi, R., and Nakajima, T.: Modelling radiation quantities and photolysis frequencies in the troposphere, J. Atmos. Chem., 18, 171-210, doi:10.1007/BF00696813, 1994.
Schaepman-Strub, G., Schaepman, M. E., Painter, T. H., Dangel, S., and Martonchik, J. V.: Reflectance quantities in optical remote sensing - definitions and case studies, Remote Sens. Environ., 103, 27-42, doi:10.1016/j.rse.2006.03.002, 2006.

Seidel, F., Schläpfer, D., Nieke, J., and Itten, K.: Sensor Performance Requirements for the Retrieval of Atmospheric Aerosols by Airborne Optical Remote Sensing, Sensors, 8, 1901-1914, doi:10.3390/s8031901, available at: http://www. mdpi.com/1424-8220/8/3/1901/, last access: 1 May 2010, 2008.

Sobolev, V. V.: Light scattering in planetary atmospheres (Translation of Rasseianie sveta v atmosferakh planet, Pergamon Press, Oxford and New York, 1975), Izdatel'stvo Nauka, Moscow, 1972.

Stamnes, K., Tsay, S.-C., Wiscombe, W., and Jayaweera, K.: Numerically stable algorithm for discrete-ordinate-method radiative transfer in multiple scattering and emitting layered media, Appl. Optics, 27, 2502-2509, doi:10.1364/AO.27.002502, 1988.

van de Hulst, H. C.: Scattering in a planetary atmosphere, Astrophys. J., 107, 220-246, available at: http://adsabs.harvard.edu/ full/1948ApJ...107..220V, last access: 1 May 2010, 1948.

van de Hulst, H. C.: Multiple light scattering, Vols. 1 and 2, Academic Press, New York, NY (USA), 1980.

Vermote, E. F., Tanré, D., Deuzé, J. L., Herman, M., and Morcrette, J.-J.: Second Simulation of the Satellite Signal in the Solar Spectrum, 6S: an overview, IEEE T. Geosci. Remote, 35, 675-686, doi:10.1109/36.581987, 1997.

Zege, E. P. and Chaikovskaya, L.: New approach to the polarized radiative transfer problem, J. Quant. Spectrosc. Ra., 55, 19-31, doi:10.1016/0022-4073(95)00144-1, 1996. 